Article

\title{
The Catalan Syndrome? Revisiting the Relationship Between Income and Support for Independence in Catalonia
}

\author{
Jordi Muñoz ${ }^{1,2}$ \\ ${ }^{1}$ Department of Political Science, Constitutional Law and Philosophy of Law, University of Barcelona, Spain; \\ E-Mail: jordi.munoz@ub.edu \\ 2 Institutions and Political Economy Research Group, University of Barcelona, Spain
}

Submitted: 21 June 2021 | Accepted: 24 August 2021 | Published: 10 December 2021

\begin{abstract}
The surge in support for independence in Catalonia (Spain) has received much political, journalistic, as well as academic attention. A popular account of the Catalan case stresses the allegation that motives relating to fiscal selfishness are behind the independence movement. The evidence presented in support of this argument is the positive correlation between income and support for independence. Some scholars, such as Thomas Piketty, even talk about a "Catalan syndrome," according to which support for independence can ultimately be explained by fiscal selfishness and the prospect of creating a sort of tax haven in Catalonia. As prominent as this argument is, in this article I show that it rests on weak theoretical and empirical grounds. In order to do so, I reassess the existing evidence, using a more nuanced empirical strategy that allows for non-linear relations to emerge and controls for potential confounders. Then, I also present new evidence based on recently published census-tract level fiscal data, merged with election results. Finally, I spell out the mechanisms and observable implications of the "Catalan syndrome" argument and show that fiscal selfishness is not an important driver of the Catalan independence movement.
\end{abstract}

\section{Keywords}

Catalonia; fiscal preferences; income; independence; Piketty; secessionism

\section{Issue}

This article is part of the issue "Secessionism in Liberal Democracies: What Do We Really Know About the Explanations of Secessionism?" edited by Ferran Requejo (Pompeu Fabra University, Spain) and Marc Sanjaume-Calvet (Pompeu Fabra University, Spain / Open University of Catalonia, Spain).

(C) 2021 by the author; licensee Cogitatio (Lisbon, Portugal). This article is licensed under a Creative Commons Attribution 4.0 International License (CC BY).

\section{Introduction}

In recent years, the question of Catalan independence has dominated the political agenda in Catalonia and Spain, and has been increasingly salient on the European stage as well. Once regarded as an example of moderate and institutionalized minority nationalism (Balcells, 1996), Catalan nationalist parties became increasingly supportive of independence from 2010 onwards. This move towards secessionist positions led to increased polarization and institutional conflict, culminating in the Autumn of 2017. A unilateral referendum on independence, heavily suppressed by the Spanish riot police, led to a series of contentious events that culminated with a declaration of independence passed by the Catalan Parliament, the suspension of the Catalan autonomy, and the imprisonment of the majority of the members of the government.

While the specific events were widely reported, the debate on the causes of this push for independence is far from settled. Both scholars and commentators have pointed in various directions. Some stress the importance of the grassroots movements (Crameri, 2015; Della Porta \& O'Connor, 2017; Muñoz \& Guinjoan, 2013), while others point in the direction of an elite-motivated movement (Barrio \& Field, 2018; Barrio \& Rodríguez-Teruel, 2017). Some accounts focus on the institutional mismatch between the Catalan self-government and the 
increasingly pro-centralization dominant interpretation of the 1978 Spanish constitution, or refer to structural factors (Dowling, 2014).

Interpreting the secessionist turn in terms of economics is quite popular in the international arena. Catalonia has an above average GDP per capita compared to the rest of Spain, and the amount of interregional transfers has been a hotly debated political issue for a long time. Therefore, the independence push is easily interpreted as being caused by the wish to stop such transfers. This argument fits with some general findings of the comparative politics literature that tends to identify relative wealth as a determinant of aggregate support for secession in regions (Sambanis \& Milanovic, 2014; Sorens, 2005). However, some recent studies also suggest that relative wealth is only important as long as there is cultural distinctiveness (Álvarez Pereira et al., 2018).

The idea of economic motivations being an important driver of the pro-independence push in Catalonia has gained traction, especially among external observers. It fits with common wisdom and is easily understood without much contextual knowledge. Indeed, there is evidence showing that economic considerations were indeed relevant to explaining support for independence, especially in the first moments of the independence push. Muñoz and Tormos (2015) showed that those respondents experimentally induced to expect positive economic effects of secession were up to five percentage points more likely to support it. However, the effect was often modest and conditional: Identity and partisanship appear as the main drivers of support for secession in a large majority of empirical models (Burg, 2015; Guinjoan \& Rodon, 2014; Serrano, 2013).

Additionally, the temporal coincidence of the independence push with the great recession led many observers to conclude that the relative scarcity of the time made the question of the interregional transfers more pressing. While many casual observers interpreted the Catalan process in the context of the great recession, there is research showing that the impact of the economic crisis is not related to the increase in support for independence (Cuadras-Morató \& Rodon, 2019). Indeed, many other political events are more likely triggers of the surge in support for independence, such as those related to the Constitutional Court ruling on the Statute of Autonomy (2010) or the victory of the right-wing, procentralization Popular Party in 2011.

A crucial debate, however, refers to the socioeconomic bases of support for independence in Catalonia. Some work points to the positive association between income and support for independence (Guinjoan \& Rodon, 2016). However, Della Porta and Portos (2020) refine the analysis and stress the broad cross-class coalition that united around the claims for self-determination. According to their analysis, the socio-economic composition of the pro-independence movement supporters was more complex and chang- ing. The anti-austerity protests in Catalonia also influenced the movement's agenda that, in turn, reshaped its social bases.

Hierro and Queralt (2020) provide a more nuanced account of the individual materialist reasons behind the independence push. They show how trade factors are relevant, especially for depressing support among those that work in firms and sectors oriented to the Spanish market. Moreover, they find a positive association between skills and support for independence but attribute it to a better understanding of how the institutional framework of fiscal transfers across regions works and, hence, higher skepticism about any potential for reform.

However, the most widely known economic interpretation of the Catalan drive for independence is the version that the French economist Thomas Piketty develops in his recent book Capital and Ideology. Piketty coins the term "Catalan syndrome" to refer to a desire of the rich to escape from fiscal solidarity via secession (Piketty, 2020, pp. 918-935). He uses the Catalan case to illustrate the challenges that fiscal selfishness from the rich pose to fiscal redistributive systems: They induce what he calls the secessionist trap. According to Piketty, the desire to escape the burden of fiscal solidarity would be the main explanation for the independence push in Catalonia. He illustrates his argument with some descriptive evidence showing a positive correlation between income and support for independence.

However, as prominent as this argument is, it rests on weak theoretical and empirical grounds. In this article, I review Piketty's argument and the supporting evidence he presents in order to show its merits and limitations. First, I analyze the theory and explicitly spell out the observable implications that remain implicit in Piketty's work. Then, I reassess the correlation between income and support for independence. In order to do so, I present two types of empirical analyses of the correlation between income and independence. The first replicates and extends the analyses of Piketty and is based on the same data he used: survey data from the Center for Opinion Studies of the Catalan Government. After discussing the results and their limitations, I present the main empirical contribution of this article: the analysis of the newly released fiscal data at the census tract level, together with election results and other census variables. As I explain below, these data allow us to overcome some of the problems caused by the use of survey data and provide a more nuanced and complex picture of the relationship between income and independence.

Finally, I also empirically test a range of observable implications of the theory regarding the role of fiscal preferences and the functional form of the relationship. The results of these tests cast doubt on the validity of the fiscal selfishness theory, as the implied mechanisms are not supported by the data. In the concluding section, I discuss why this may be the case and present some alternative explanations. 


\section{Theory}

As discussed above, there are many different explanations for the recent increase in support for secession in Catalonia. Some are purely political, while others privilege economic self-interest. A quite widespread interpretation is the so-called "revolt of the rich." According to this theory, Catalans' support for secession is explained by their relatively privileged position within Spain.

The "revolt of the rich" theory has many proponents. Most notably, Thomas Piketty, in his book Capital and Ideology, talks about the "Catalan Syndrome" and puts forward the fiscal selfishness argument (Piketty, 2020). Piketty suggests that high-income Catalans aim for an independent country to get a Luxembourg type of fiscal haven. This would explain not only why the proindependence movement grew in Catalonia and not elsewhere in Spain but also why there is a positive correlation between income and support for independence within Catalonia. In Piketty's argument, the driver of this correlation within Catalonia must be fiscal preferences. The argument is as follows: The (Catalan) rich carry the burden of inter-territorial redistribution, so they are interested in secession. On the contrary, (Catalan) working classes are more supportive of fiscal solidarity and redistribution, given that they themselves are net beneficiaries of redistribution. Therefore, the independence drive should be (at least in part) motivated by the desire to set a low-tax system in Catalonia. Once relieved from the burden of fiscal transfers to the rest of Spain, taxes in Catalonia could be lowered.

Given the full theory, it is obvious that the mere correlation of income and pro-independence attitudes does not provide sufficient evidence in support of this specific theory. This correlation may be spurious, or it may be driven by different mechanisms other than those implied by Piketty's argument. While Piketty provides evidence on the association between income and support for independence based on survey data, such a correlation may be informative but is insufficient to demonstrate the fiscal selfishness argument.

There are several key observable implications that we should assess if we want to rigorously test the theory, but Piketty does not test them. First, the association between income and independence support should be causal and not spurious. In other words, it should not be explained by unobserved confounders. Second, if Piketty's argument was correct, we should observe that pro-independence supporters have distinct fiscal preferences: They should prefer lower taxes than those that oppose independence. A third and rather straightforward implication of the argument is that support for independence should increase monotonically with income and perhaps at a marginally increasing slope.

Testing these implications is the fundamental contribution of this article. First, I explore the correlations in more detail and then assess them one by one, using different sources of data.

\section{Empirics: Reassessing the Correlation}

In this section, I first reassess the main finding that Piketty presents in support of his argument, and then I provide a more systematic test of the observable implications of his theory. In doing so, I point to several shortcomings of the existing evidence that I attempt to overcome.

First, Piketty's data is exclusively based on public opinion surveys, just like virtually all other works that advance different versions of the economic explanation of support for independence. While these surveys constitute a crucial source of individual-level data, they are nonetheless subject to sampling and reporting problems. These problems are especially acute at both ends of the income distribution, as they are more difficult to interview. Moreover, the income variable is subject to a severe problem of non-response and misreporting (Neri \& Zizza, 2010). This is why, in this article, I supplement the analysis of the survey data with an analysis of a novel register-based dataset at the census-tract level. Census tracts are small geographical areas, with an average of 1,000 voters. Merging various sources of data allows us to know the average income of the area, the electoral results, and crucially, some key control variables such as language, age composition, and place of birth.

The second limitation is that the evidence presented in support of the argument is based on bivariate correlations that do not have a causal interpretation. Indeed, these correlations could simply be spurious, as I discuss below. High- and low-income voters are different in other, non-economic dimensions, which may explain the observed association. In order to address this possibility, in reassessing the evidence, I include a limited set of controls. In order to avoid a potential problem of posttreatment bias that may erroneously push down the estimate of the correlation between income and support for independence, I limit the control variables to a handful of clearly exogenous variables. I am extremely cautious in not including any control variable that could be endogenous to income.

Finally, in the correlational analyses, linearity is frequently imposed by assumption. While the theory predicts a monotonically increasing relationship between income and support for independence, this is an empirical question that should be subject to empirical scrutiny. This is what I do below by relaxing the linearity assumption and allowing a non-linear pattern of relation between the two variables to emerge.

\subsection{Survey Evidence}

First, I use the same data sources as Piketty and most other works on support for independence: the public opinion surveys by the Catalan government's official Center of Opinion Studies (CEO). The CEO is a government-run office controlled by an expert and plural government body and holds high standards of transparency and data quality. Data and full documentation 
are publicly available on the CEO website. The CEO runs a quarterly Public Opinion Barometer and has maintained an up-to-date cumulative file with all waves since 2014. Data quality and availability make this source of data very popular among researchers of Catalan politics. For completeness, in my analysis, I use the cumulative CEO dataset, which includes the surveys conducted between 2014 and 2020.

The analysis is quite straightforward. Essentially, I regress support for independence on declared family income. The dependent variable is a dichotomous question on whether the respondent supports independence. Therefore, the models I estimate are Linear Probability Models, in which the coefficients can be interpreted as expressing the expected change in the probability of supporting secession.

In order to address the question of potential spuriousness, I estimate two models: a simple bivariate regression, akin to the bivariate correlations that are often presented by the literature, and also a multivariate model that includes a full set of controls-family origin, language (mother tongue), age, and size of municipality and province. Family origin and language combined account for Catalan citizens' cultural heritage, which can adopt multiple combinations of place of birth, ancestry, and language. I also include survey fixed effects to account for time variation. The only caveat is that in the simple model, I also include a control for the number of people living in the household, as income is measured at the household and not at the individual level. Otherwise, the results could be confounded by varying sizes of household. Table 1 presents the results of these two models.

The models in Table 1 clearly show how income is positively associated with support for independence in the bivariate model. The coefficient remains statistically significant but is much smaller in the full model with the language, origin, and place of residence controls. Cultural factors and family origin matter substantially more. Those who speak Catalan and those born in Catalonia, especially from Catalan-born parents, are much more likely to support independence. These results are not surprising in the context of the literature. Another important piece of evidence comes from the $R$-squared. The fit of the models also points to the limited explanatory power of income: The model with income alone shows a very poor fit (0.03) while the full model with controls has a much higher fit (0.37).

In order to make the results more easily interpretable and allow for a non-linear relation to emerge, I plot predicted values of the dependent variable at each income segment as recorded by the CEO in Figure 1 . In this case, instead of treating income as a continuous variable, I use a set of dummies for each income level. Results of this empirical exercise are presented in Figure 1. There are

Table 1. Household income and support for independence, 2014-2020.

\begin{tabular}{|c|c|c|}
\hline & Simple model & Full model \\
\hline \multirow[t]{2}{*}{ Household income } & $0.03 * * *$ & $0.01 * * *$ \\
\hline & 0.00 & 0.00 \\
\hline \multirow[t]{2}{*}{ Size of household } & $-0.02 * * *$ & $-0.01 *$ \\
\hline & 0.00 & 0.00 \\
\hline \multirow[t]{2}{*}{ 1st generation, mixed } & $-0.05 * * *$ & \\
\hline & & -0.01 \\
\hline \multirow[t]{2}{*}{ 1st generation born in Catalonia } & & $-0.07 * * *$ \\
\hline & & -0.01 \\
\hline \multirow[t]{2}{*}{ Born in rest of Spain } & & $-0.11 * * *$ \\
\hline & & -0.01 \\
\hline \multirow[t]{2}{*}{ Speaks Spanish } & & $-0.45^{* * *}$ \\
\hline & & -0.01 \\
\hline \multirow[t]{2}{*}{ Bilingual } & & $-0.29 * * *$ \\
\hline & & -0.01 \\
\hline \multirow[t]{2}{*}{ Other languages } & & 0.12 \\
\hline & & -0.22 \\
\hline \multirow[t]{2}{*}{ Age } & & $0.00 * * *$ \\
\hline & & 0.00 \\
\hline \multirow[t]{2}{*}{ Size of municipality } & & $-0.01 * * *$ \\
\hline & & 0.00 \\
\hline \multirow[t]{2}{*}{ Intercept } & $0.21 * * *$ & $0.30 * * *$ \\
\hline & -0.01 & -0.02 \\
\hline $\mathrm{N}$ & 23,370 & 23,370 \\
\hline$R^{2}$ & 0.03 & 0.37 \\
\hline
\end{tabular}

Notes: ${ }^{*} \mathrm{p}<0.1,{ }^{* *} \mathrm{p}<0.05,{ }^{* * *} \mathrm{p}<0.01$. Source: Center of Opinion Studies (2014-2020). 


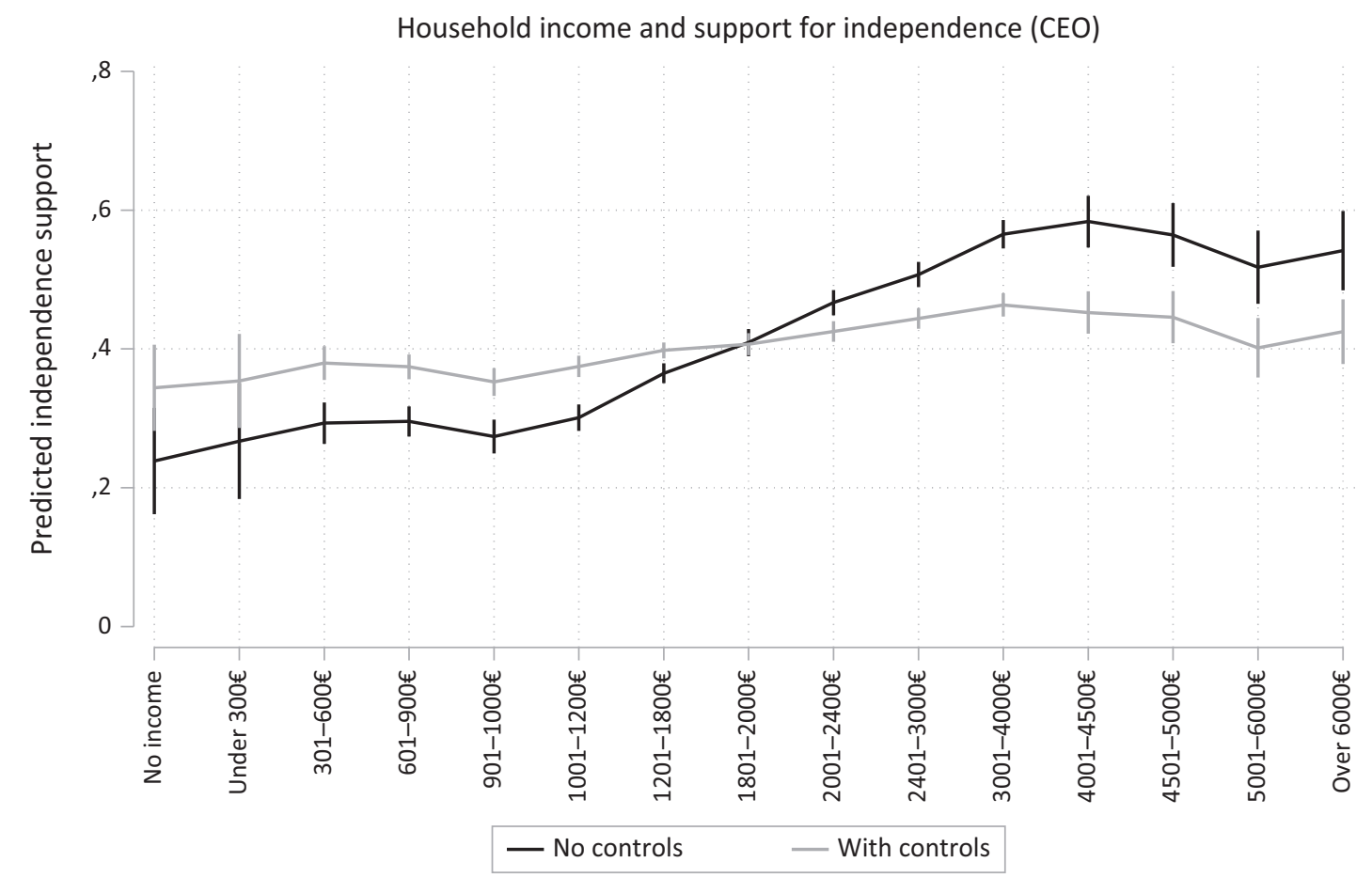

Figure 1. Income and voting for pro-independence parties.

two lines in the figure: The dark line corresponds to the bivariate model, with income and size of household only, and the lighter line corresponds to the multivariate regression with the full set of controls.

The first thing to note from the results in Figure 1 is that the bivariate correlation supports the strong association between income and support for independence that Piketty, among others, identified. Using the full CEO dataset, we see how lower-income respondents have an average level of support of about $30 \%$, while the upper segment of the distribution is located at about $60 \%$.

This substantial difference, however, is not linked to a strong predictive power of the income variable. The $R$-squared of the bivariate model is just 0.03 . This indicates that income is, by itself, a poor predictor of support for independence. While, on average, differences in support across income groups are large, there is much larger variation within income groups. With such a poor fit, any interpretation of the Catalans' support for secession as a by-product of material interest must be qualified.

If we look at the full model, represented in the grey line, we can see how, once we account for differences in language, origin, age, and type of municipality, differences in predicted support for independence among income groups become much smaller. While we still observe some positive correlation, the range of variation of predicted levels of support is much narrower: between $35 \%$ for the low-income groups and $45 \%$ for the high-income respondents. From a 30 percentage point gap to a 10 percentage point difference. Moreover, as it was already apparent in the bivariate model, the relationship is far from linear and monotonic. In the high-income group, we see, indeed, some reversal of the trend. If any- thing, at the top of the distribution, support is somewhat lower than in the upper-middle group. Below I discuss this in more detail. Also, it is worth noting that this full model is more explanatory than the bivariate one, with an $R$-squared of 0.25 .

\subsection{Aggregate Data}

The results above were based on the commonly used CEO datasets. However, in order to overcome the shortcomings of the survey data, I propose an additional empirical exercise based on census-tract data. While the use of aggregate data to infer individual patterns may be subject to a problem of ecological inference (King, 2013), the fact that we use small areas helps ameliorate it. Moreover, the quality of the data, which is free from the sampling and reporting issues that survey data suffer, may compensate for possible ecological inference problems. There are over 5,000 census tracts in Catalonia, with an average adult population of 1,099 voters.

In order to replicate the analysis at the census-tract level, I built a dataset in which I combined different sources of data. First, I measure income using tax return data provided by the Spanish national statistical institute (INE). The recently released INE dataset computes several indicators at the census-tract level based on fiscal information. Most notably, the dataset includes the 2017 average individual income as recorded in tax returns.

In order to measure support for independence at the census-tract level, I use the 2017 election results. I aggregate the vote for the three pro-independence parties (the centre-right Junts, the centre-left ERC [Esquerra Republicana de Catalunya], and the radical left CUP 
[Candidatura d'Unitat Popular]) that run in the heavily polarized election of December 2017. The election, held shortly after the declaration of independence, the suspension of the Catalan autonomy, and the subsequent imprisonment or prosecution of the previous Catalan government, was generally regarded as a plebiscite on independence (Martí \& Cetrà, 2016; Orriols \& Rodon, 2016). While some other issues may drive voters' choices, arguably, that particular election was mostly about secession, so we can confidently use party support as an indicator of support for independence.

Using these data, I try to mimic the survey analysis as closely as possible. In order to do so, I regress vote for pro-independence parties in 2017 on average personal income at the census-tract level. As before, I estimate a bivariate regression and a multivariate model with controls, which include the share of population born in the rest of Spain, the share of the population that can speak Catalan, share of the population over 65, and size of municipality and administrative region fixed effects. Controlling for language and place of birth allows us to estimate the income effect net of any potential cultural or ethnic background confounder. Table 2 shows the results of four models: Models 1 and 2 impose a linear relation between income and pro-independence vote, while the remaining two models use the squared average income to allow a non-linear pattern to emerge.

Results indicate that if we impose a linear relation between income and pro-independence vote, we find a modest effect that quickly vanishes and becomes statistically indistinguishable from zero, once we introduce the basic controls. This points to the fact that it is mostly spurious. Moreover, if we look at the fit of the models, we can see how the bivariate model has a very low $R$-squared (0.07).
However, in columns 3 and 4 of the table, where I include a quadratic term, we observe how an inverse U-shaped relationship fits the data much better. The $R$-squared increases substantially, and the coefficients remain significant even after the inclusion of controls, albeit much reduced. This points to the limitations of the models that assume linearity. In this case, it becomes obvious that a quadratic term improved the fit and provides a more appropriate description of the relationship. As I discuss below, this indicates that there is a distinct behavior at the top of the income distribution, where we observe much less support for independence. This is important for the interpretation of the results.

In order to provide a better visualization of the models, I represent the relationship in Figure 2. In this case, I use a vector of income decile dummies in order to allow the flexible non-linear pattern to emerge with less parametrization. As before, two lines indicate the predicted level of support for independence at various income levels, together with the $95 \%$ confidence intervals. The dark line is calculated using the bivariate model estimates, while the grey line is derived from the multivariate regression. The bivariate association is strong and positive: On average, at the $10 \%$ poorest census tracts (the bottom decile), the pro-independence parties obtained around $37 \%$ of the vote, while in the top four deciles, they reached around $55 \%$.

When we introduce the control variables in the model, the estimated income effect is substantially weaker: Everything else being equal, the difference between the predicted support for pro-independence parties in the low-income census tracts and the highincome areas is between five and eight percentage points. Moreover, in this case, the predicted increase is no longer monotonic, and we observe a small

Table 2. Income and pro-independence vote (2017), census-tract level.

\begin{tabular}{|c|c|c|c|c|}
\hline & $\begin{array}{c}1 \\
\text { Bivariate }\end{array}$ & $\begin{array}{c}2 \\
\text { Multivariate }\end{array}$ & $\begin{array}{c}3 \\
\text { Bivariate }\end{array}$ & $\begin{array}{c}4 \\
\text { Multivariate }\end{array}$ \\
\hline Average income (thousands $€$ ) & $\begin{array}{r}1.47^{*} \\
(-0.65)\end{array}$ & $\begin{array}{c}0.32 \\
(-0.37)\end{array}$ & $\begin{array}{l}9.39 * * * \\
(-1.37)\end{array}$ & $\begin{array}{l}4.93^{* * *} \\
(-0.7)\end{array}$ \\
\hline Av. income squared & & & $\begin{array}{l}-0.25^{* * *} \\
(-0.04)\end{array}$ & $\begin{array}{l}-0.14^{* * *} \\
(-0.02)\end{array}$ \\
\hline Share born rest of Spain & & $\begin{array}{l}-0.79 * * * \\
(-0.04)\end{array}$ & & $\begin{array}{l}-0.83^{* * *} \\
(-0.03)\end{array}$ \\
\hline Share speaks catalan & & $\begin{array}{l}0.53^{* * *} \\
(-0.02)\end{array}$ & & $\begin{array}{l}0.39 * * * \\
(-0.05)\end{array}$ \\
\hline Share over 65 & & $\begin{array}{l}0.53^{* * *} \\
(-0.07)\end{array}$ & & $\begin{array}{l}0.47^{* * * *} \\
(-0.1)\end{array}$ \\
\hline Size municipality (log) & & $\begin{array}{c}-0.67 \\
(-0.55)\end{array}$ & & $\begin{array}{c}-0.67 \\
(-0.41)\end{array}$ \\
\hline Intercept & $\begin{array}{l}29.42 * * * \\
(-7.85)\end{array}$ & $\begin{array}{l}24.58^{* * *} \\
(-2.76)\end{array}$ & $\begin{array}{l}-28.15^{* *} \\
(-10.65)\end{array}$ & $\begin{array}{c}1.35 \\
(-3.62)\end{array}$ \\
\hline $\mathrm{N}$ & 4,863 & 4,137 & 4,863 & 4,137 \\
\hline$R^{2}$ & 0.07 & 0.76 & 0.17 & 0.78 \\
\hline
\end{tabular}

Notes: Standard errors in parentheses; ${ }^{*} p<0.05,{ }^{* *} p<0.01,{ }^{* * *} p<0.001$. 


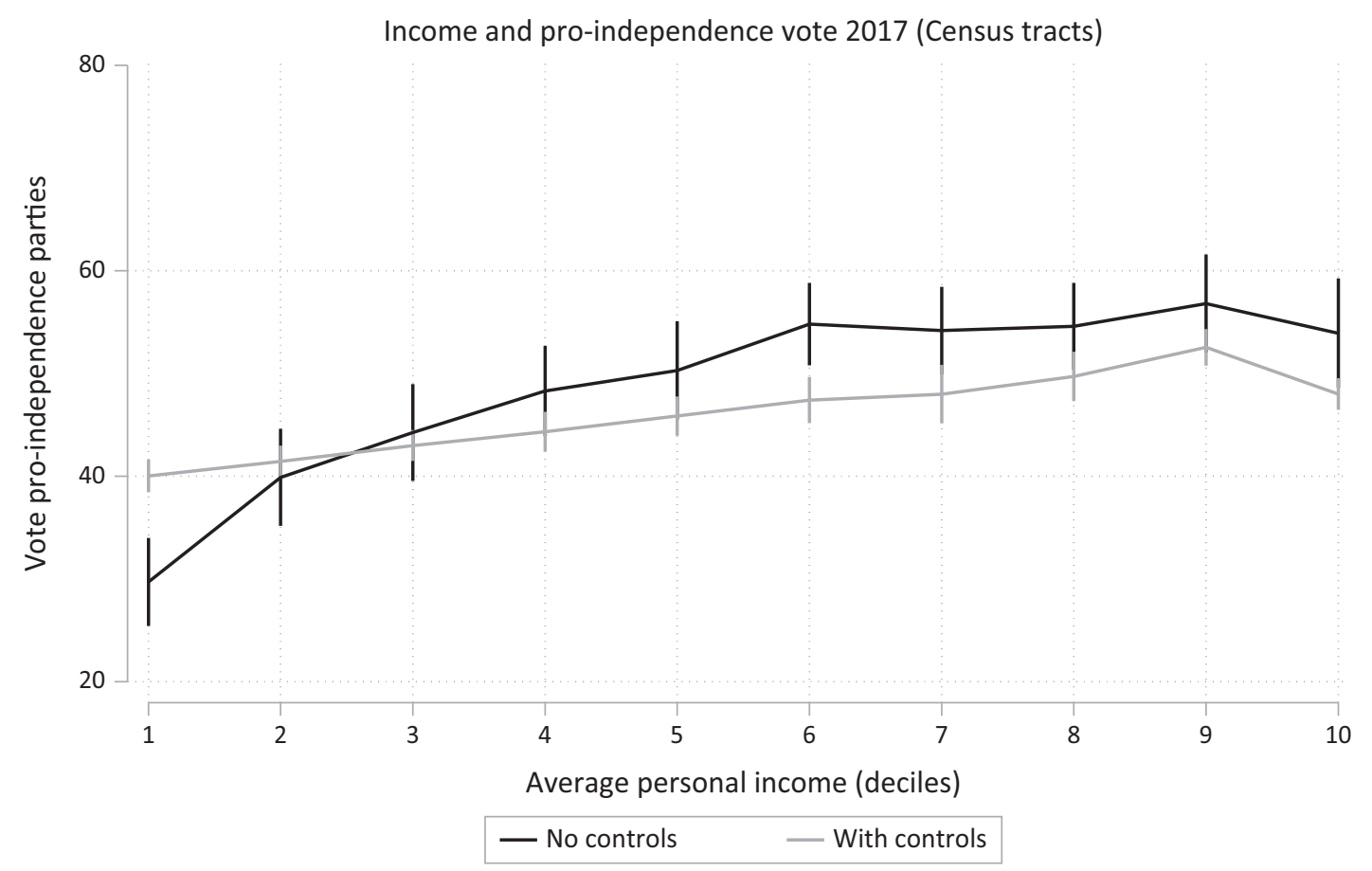

Figure 2. Income and voting for pro-independence parties, census-tract level.

decrease in the top decile. I explore this issue in further detail below.

Taken together, these analyses indicate that the strong bivariate association between income and support for independence is largely spurious, and if anything, non-linear. The key controls seem to be language and origin: The Spanish-speaking population and the population born in (or with roots in) the rest of Spain tends to express lower support for independence, and they have, on average, a lower income. This is suggestive evidence that the causal story of income and support for independence based on a fiscal selfishness argument may not hold. It may just be a by-product of cultural differences. This is, of course, relevant from a descriptive point of view, but the fact that the income effect rapidly vanishes is crucial to interpret it correctly. In order to delve more deeply into this question, in the next section I assess the mechanisms implied by Piketty's theory to see if they have empirical support.

\section{Mechanisms}

While Piketty (2020) enunciates a rather detailed argument on the mechanism of fiscal selfishness as the driver of the association between income and support for independence, he does not test the additional observable implications. This is important to test the theory, and more so after having established that the correlation is largely explained by other variables, and is best described as a non-linear relation.

Even if Piketty does not spell them out systematically, from reading his argument we can easily derive some straightforward observable implications of the theory. The first implication obviously relates to tax preferences:
If the desire for lower taxes is the main driver of the correlation between income and support for independence, we should observe that those who favor secession prefer lower taxes than those who oppose it. This is the core of the Catalan syndrome argument. If it is an appropriate interpretation of the secessionist turn, then fiscal preferences should differ among supporters and opponents of secession.

In Figure 3, I explore this question. Using the same dataset used in Table 1, I plot the share of pro- and anti-independence respondents in the CEO surveys that support and oppose lowering taxes, even if it comes at the expense of lower funding for public services. As the figure shows, there is only a very minor difference in attitudes to taxation across pro- and anti-independence groups. In both groups, opposition to tax cuts is predominant, but if anything, independence supporters are less and not more supportive of tax cuts.

The fact that pro-independence attitudes are correlated with slightly more, and certainly not less, support for tax-based redistribution questions the validity of the fiscal selfishness argument. Tax preferences do not seem to be an important driver of support for independence. Remarkably, this is congruent with actual policy outcomes: As Agrawal and Foremny (2019) show, since 2014, when the decision of part of the marginal rates of the income tax was decentralized, the (pro-independence) Catalan governments did not lower taxes for the highincome citizens. On the contrary, the Catalan marginal tax rate increased up to two percentage points for those earning over $100,000 €$ with respect to the baseline central rate. Somewhat paradoxically, it was the regional government of the province of Madrid who decided to lower taxes for the upper-income segments. Therefore, 


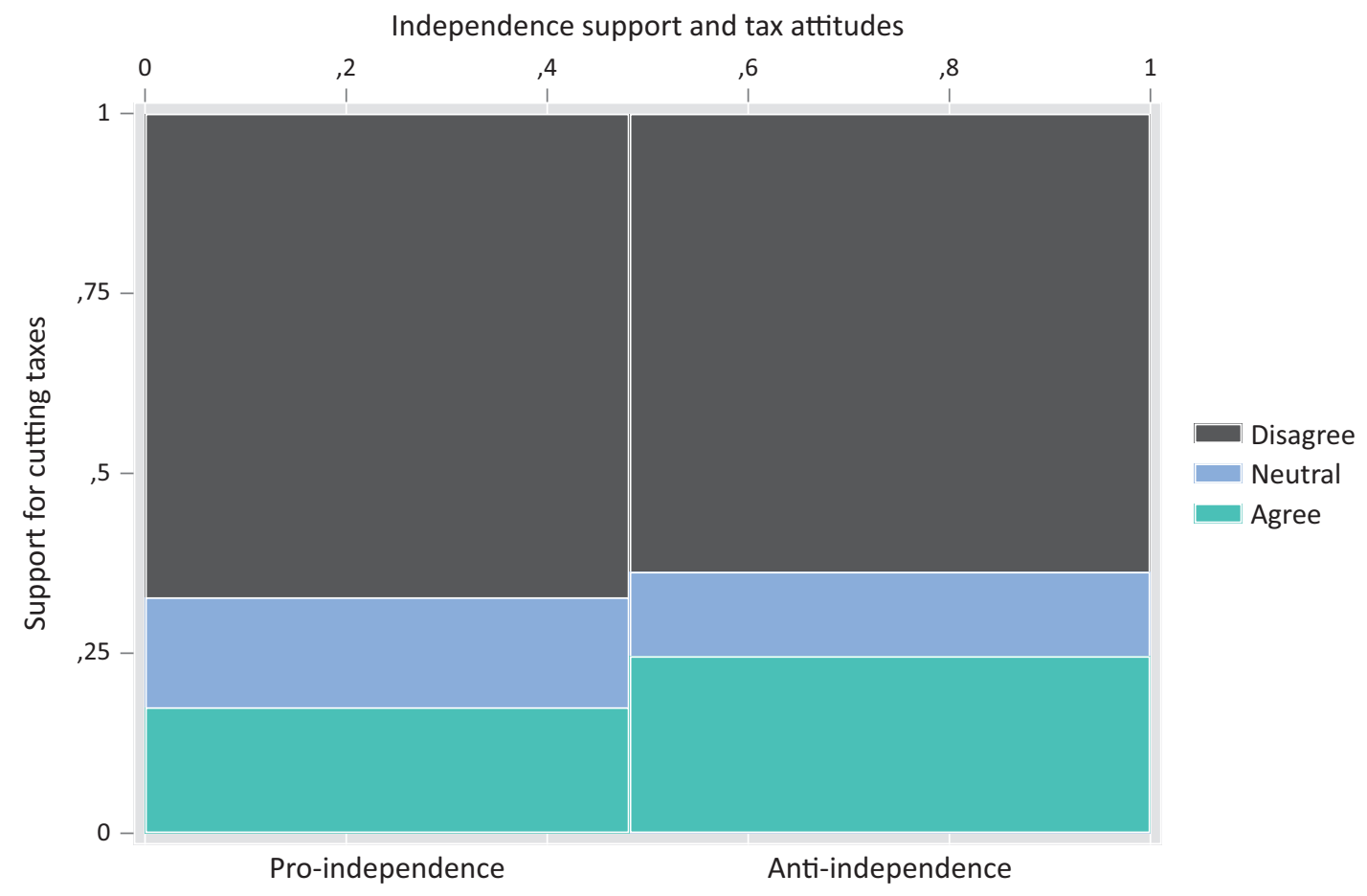

Figure 3. Support for independence and tax attitudes.

the core of the debate was not related to the tax rates but to which government had the authority to set them. And, if anything, the Catalan government was willing to increase taxes and the progressivity of the system during the period of heightened secessionist tensions.

Another observable implication that we can explore in more detail is the linearity and monotonicity of the correlation. In accordance with the Catalan syndrome argu- ment, if the quest for a Luxembourg-style fiscal haven was a relevant driver of support for independence in Catalonia, the top incomes should be disproportionately more and not less supportive of secession. They would be the most to financially benefit from secession. In the models presented above, we can already see some downward trend at the top of the distribution. In Figure 4, I replicate the same analysis as in Figure 2 but using an

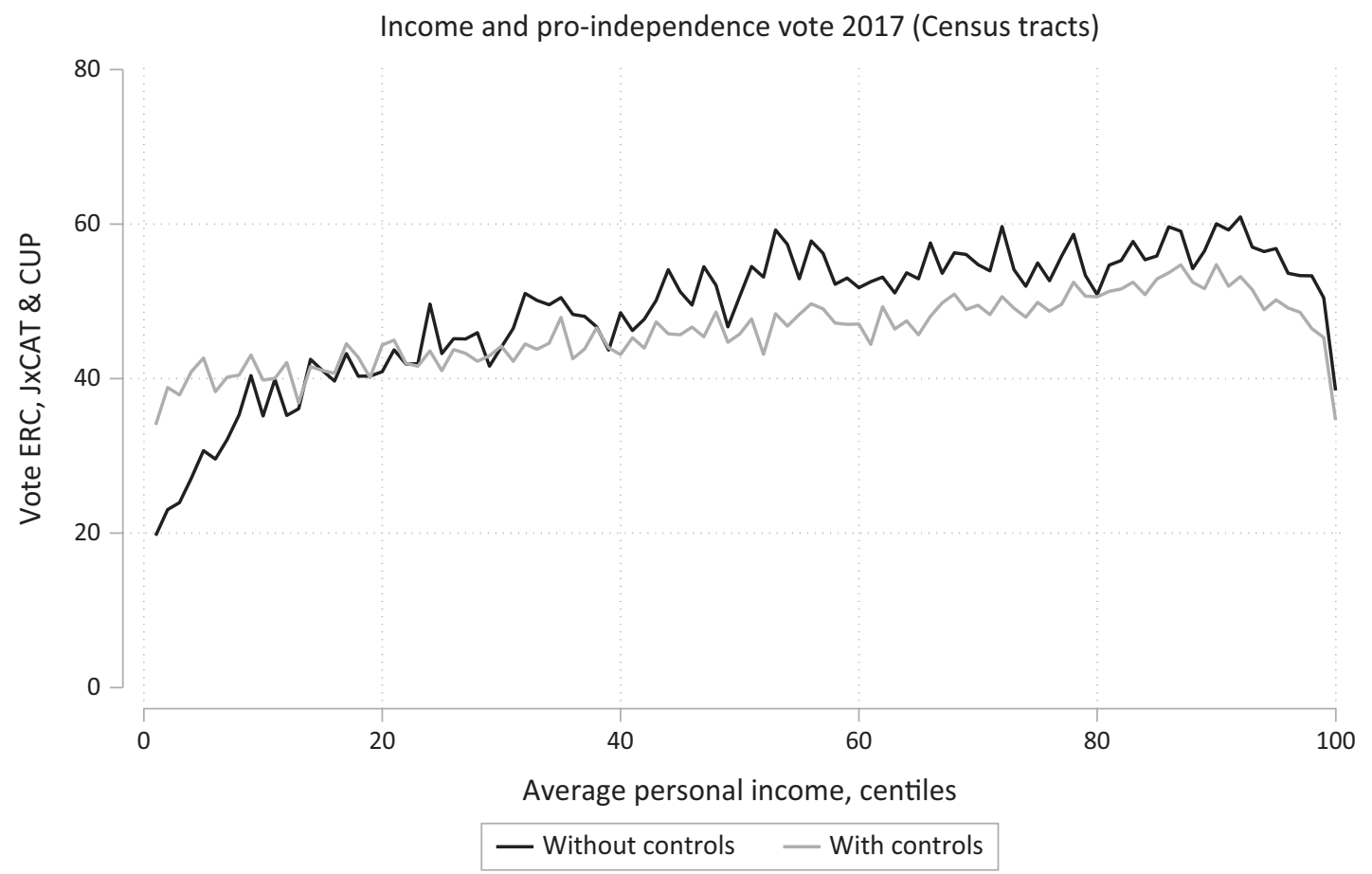

Figure 4. Support for independence and income centiles. 
even more fine-grained approach: Instead of the income deciles, I use the centiles. This allows for full flexibility in the estimation.

Results in Figure 4 show the downward trend in the top $10 \%$ even more clearly. Most interestingly, this downward trend is very sharp among the top $1 \%$-a very particular group. The census tracts in which those with the highest incomes live show substantially less support for independence than the majority of the distribution. Only the bottom $20 \%$ has a lower pro-independence vote than the top $1 \%$.

Taken together, these results call the fiscal selfishness argument into question. First, the association between income and support for independence is largely explained by origin and language. Second, there is no evidence whatsoever that preferences for lower taxes are the driver of support for independence. Crucially, pro-independence respondents express slightly more favorable views of fiscal transfers. And, finally, it is important to note that the correlation between income and support for independence is not linear. The top incomes (those that would arguably benefit disproportionately from a Luxembourg-style tax haven) show less, and not more, support for secessionist parties when compared with the majority of the distribution.

\section{Discussion and Conclusions}

As we have seen, the correlation between income and support for independence is highly sensitive to the type of data we use, to the inclusion of control variables, and to the relaxing of the linearity assumption. Moreover, some key implications of the "fiscal selfishness" theory do not hold when subject to closer scrutiny: Pro-independence respondents are less, and not more supportive of tax cuts. And at the very top of the income distribution, there is a relevant downward trend in support for independence.

If the reason is not fiscal selfishness, how can we explain the correlation we found between income and support for independence? There are essentially two alternative explanations. The first being that the correlation is merely spurious and has no causal interpretation. Other non-economic confounding factors (most notably, family origin/language) may explain the observed association. This is what I have tested in the models in which I included the controls. As evident, both in the survey and the aggregate data, these factors account for a large part of the association between income and support for independence.

Essentially, this is related to the fact that a substantial part of the Catalan population was born in or descended from people born in other regions of Spain. During the period of approximately 1950-1970, a huge migration inflow, especially from southern Spain, populated the industrial areas of Catalonia. It was not the first massive immigration wave that Catalonia experienced during the 20th century: An early and intensely industrial- ized region attracted large numbers of workers from rural areas. Today these immigrants, and to some extent also their offspring, are more likely to have Spanish and not Catalan as their mother tongue, have a relatively lower average income, and express less support for secession. Therefore, the main driver of the observed pattern is not the financial considerations but the cultural differences.

However, in these models, there is still some remaining association that is unaccounted for by the control variables. Once we control for origin and language, it becomes much weaker but still statistically significant. A possible explanation is that we are missing some additional controls.

Nonetheless, another possibility is that this correlation is caused by other economic factors that may correlate with income but express a different story. Some recent work has tried to address them. Hierro and Queralt (2020) show that respondents working at sectors and firms specializing in the Spanish market are more reluctant toward independence, while those specializing in foreign markets are no more opposed. They also find an association with skill levels that they attribute to a better understanding of the institutional context of redistribution and hence a higher skepticism with regards to the possibilities of accommodation of regional demands within Spain. This work probably points in the direction that the research on the political economy of secessionism in Catalonia should go: a more nuanced approach that also considers Catalonia's complex trade relations with Spain and the rest of Europe.

Summing up: In this article, I have shown that the correlation between income and support for independence in Catalonia is in large part explained away by cultural and linguistic factors. In addition, the fit of the simple models in which I regressed support for independence on income was extremely poor: Income, by itself, is hardly predictive of support for independence.

Moreover, the pattern of association is clearly not linear: As we move towards the very top of the income distribution, support for independence goes down. Nevertheless, most importantly, the main finding that I have presented here is that fiscal attitudes are not drivers of this correlation, as implied in Piketty's "Catalan syndrome" argument. I believe that taken together, all these pieces of evidence cast doubt on the fiscal selfishness argument and point to the need for a more nuanced understanding of the recent surge in pro-independence attitudes in Catalonia. There is abundant evidence that economic considerations are not the main driver of public opinion, and in any case, the economic factors are more complex than the pure fiscal selfishness argument implies, in spite of this argument regularly being put forward by certain observers, pundits, and scholars.

\section{Acknowledgments}

I wish to thank the participants of the workshop on "Explanatory factors of secessionism" organized by the 
Institute of Self-Government Studies (IEA) in Barcelona, November 2020. I also thank Alejandra Suárez for her extremely efficient research assistance.

\section{Conflict of Interests}

The author declares no conflict of interest.

\section{References}

Agrawal, D. R., \& Foremny, D. (2019). Relocation of the rich: Migration in response to top tax rate changes from Spanish reforms. Review of Economics and Statistics, 101(2), 214-232.

Álvarez Pereira, B., Portos, M., \& Vourdas, J. (2018). Waving goodbye? The determinants of autonomism and secessionism in Western Europe. Regional Studies, 52(2), 197-211.

Balcells, A. (1996). Catalan nationalism: Past and present. Springer.

Barrio, A., \& Field, B. N. (2018). The push for independence in Catalonia. Nature Human Behaviour, 2(10), 713-715.

Barrio, A., \& Rodríguez-Teruel, J. (2017). Reducing the gap between leaders and voters? Elite polarization, outbidding competition, and the rise of secessionism in Catalonia. Ethnic and Racial Studies, 40(10), 1776-1794.

Burg, S. L. (2015). Identity, grievances, and popular mobilization for independence in Catalonia. Nationalism and Ethnic Politics, 21(3), 289-312.

Center of Opinion Studies. (2014-2020) Political opinion barometer: Cumulative file [Data set]. https://ceo. gencat.cat/ca/barometre/matrius-fusionada-BOP

Crameri, K. (2015). Political power and civil counterpower: The complex dynamics of the Catalan independence movement. Nationalism and Ethnic Politics, 21(1), 104-120.

Cuadras-Morató, X., \& Rodon, T. (2019). The dog that didn't bark: On the effect of the Great Recession on the surge of secessionism. Ethnic and Racial Studies, 42(12), 2189-2208.

Della Porta, D., \& O'Connor, F. (2017). Social movements and referendums from below: Direct democracy in the neoliberal crisis. Policy Press.

Della Porta, D., \& Portos, M. (2020). A bourgeois story? The class basis of Catalan independentism. Territory,
Politics, Governance, 9(3), 1-21.

Dowling, A. (2014). Accounting for the turn towards secession in Catalonia. International Journal of Iberian Studies, 27(2/3), 219-234.

Guinjoan, M., \& Rodon, T. (2014). Beyond identities: Political determinants of support for decentralization in contemporary Spain. Regional \& Federal Studies, 24(1), 21-41.

Guinjoan, M., \& Rodon, T. (2016). Catalonia at the crossroads. Analysis of the increasing support for secession. In X. Cuadras-Morató (Ed.), Catalonia: A new independent state in Europe?: A debate on secession within the European Union (pp. 20-65). Routledge.

Hierro, M. J., \& Queralt, D. (2020). The divide over independence: Explaining preferences for secession in an advanced open economy. American Journal of Political Science, 65(2), 422-442.

King, G. (2013). A solution to the ecological inference problem. Princeton University Press.

Martí, D., \& Cetrà, D. (2016). The 2015 Catalan election: A de facto referendum on independence? Regional \& Federal Studies, 26(1), 107-119.

Muñoz, J., \& Guinjoan, M. (2013). Accounting for internal variation in nationalist mobilization: Unofficial referendums for independence in Catalonia (2009-11). Nations and nationalism, 19(1), 44-67.

Muñoz, J., \& Tormos, R. (2015). Economic expectations and support for secession in Catalonia: Between causality and rationalization. European Political Science Review, 7(2), 315-341.

Neri, A., \& Zizza, R. (2010). Income reporting behaviour in sample surveys (Working Paper No. 777). Bank of Italy.

Orriols, L., \& Rodon, T. (2016). The 2015 Catalan election: The independence bid at the polls. South European Society and Politics, 21(3), 359-381.

Piketty, T. (2020). Capital and ideology. Harvard University Press.

Sambanis, N., \& Milanovic, B. (2014). Explaining regional autonomy differences in decentralized countries. Comparative Political Studies, 47(13), 1830-1855.

Serrano, I. (2013). Just a matter of identity? Support for independence in Catalonia. Regional \& Federal Studies, 23(5), 523-545.

Sorens, J. (2005). The cross-sectional determinants of secessionism in advanced democracies. Comparative Political Studies, 38(3), 304-326.

\section{About the Author}

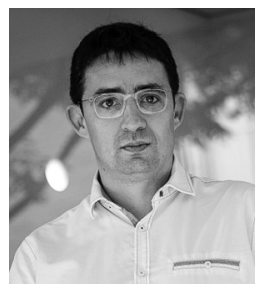

Jordi Muñoz is an associate professor at the Department of Political Science, Constitutional Law and Philosophy of Law of the University of Barcelona, and a fellow at the Institutions and Political Economy Research Group. He holds an ICREA Academia Award. He got his PhD from Pompeu Fabra University (2009). He was a postdoctoral researcher at the Autonomous University of Barcelona and visiting researcher at the University of Gothenburg (2012) and Yale University (2007-2008). His work has appeared in journals such as The Journal of Politics, Political Analysis, Comparative Political Studies, and Political Science Research and Methods, among others. 